\title{
METHYLENETETRAHYDROFOLATE REDUCTASE POLYMORPHISMS AS POSSIBLE RISK FACTORS OF VENOUS THROMBOSIS - TOO WEAK TO TAKE CARE, TOO FREQUENT TO BE IGNORED...
}

Alicja Krejner, Tomasz Grzela

Department of Histology and Embryology, Medical University of Warsaw

\begin{abstract}
Methylenetetrahydrofolate reductase (MTHFR) is an enzyme involved in the metabolism of homocysteine. It has been found that an increased concentration of homocysteine in circulating blood (hyperhomocysteinaemia) may lead to blood vessel damage, which may further be associated with higher risk of various cardiovascular disorders, including venous thrombosis (VT). Among various factors identified to be responsible for hyperhomocysteinaemia, an important role is played by the genetically determined decrease of MTHFR enzymatic activity. This decrease may result from several nucleotide polymorphisms (SNPs) of the gene encoding for MTHFR, with the two most important SNP variants: C677T and A1298C. However, the exact role of the mentioned polymorphisms in the pathogenesis of venous thrombosis remains unclear, especially since the results of several studies conducted so far were inconsistent and did not confirm univocally any such direct relationship. In this review the authors aim to explain the reason of such a discrepancy. Moreover, the authors try to answer the question, whether both mentioned polymorphic variants of the MTHFR gene (C677T and A1298C) are in fact considerable risk factors for venous thrombosis. Based on various pro and contra published so far, the authors conclude that polymorphisms of MTHFR, although recognised as rather weak single risk factors of VT, cannot be underestimated and still require our attention.
\end{abstract}

Key words: homocysteine, MTHFR, polymorphism, SNP, thrombosis.

\section{REVIEW PAPER}

Phlebological Review 2014; 22, 2: 62-67

DOI: $10.5114 /$ pr.2014.48907

Submitted: 31.10 .2014

Accepted: 9.12 .2014

\section{ADDRESS FOR CORRESPONDENCE: \\ Tomasz Grzela, MD, PhD \\ Department of Histology and Embryology Medical University of Warsaw \\ Chałubińskiego 5, 02-004 Warszawa \\ e-mail: tomekgrzela@gmail.com}

\section{INTRODUCTION}

Methylenetetrahydrofolate reductase (MTHFR) is a key enzyme involved in homocysteine ( $\mathrm{HCy}$ ) metabolism [1]. It converts 5,10-methylenetetrahydrofolate to 5 -methyltetrahydrofolate. The latter compound serves as the donor of methyl groups for the vitamin $\mathrm{B}_{6}$ - and $\mathrm{B}_{12}$-dependent remethylation of homocysteine to methionine. It is noteworthy that the folate pathway is also involved in the generation of purines, which are necessary for the synthesis of RNA and DNA molecules [2]. Homocysteine is metabolised in the kidney by an alternative pathway of transsulphuration, where in the first step HCy is condensed with serine to form cystathionine, which is then broken down into cysteine, followed by its further conversion into taurine and sulphate (Fig. 1).

\section{HYPERHOMOCYSTEINAEMIA}

In normal conditions both pathways are usually sufficient to maintain the HCy serum concentration below the level of 12-15 $\mu \mathrm{mol} / \mathrm{l}$. However, kidney insufficiency, deficiency of folic acid, vitamins $\mathrm{B}_{6}$ and $\mathrm{B}_{12}$, or any dys- function of enzymes involved in HCy metabolism may result in hyperhomocysteinaemia [3]. According to the American Heart Association, serum concentrations of $15-31 \mu \mathrm{mol} / \mathrm{l}$ were considered as mildly increased, $31-100 \mu \mathrm{mol} / \mathrm{l}$ as intermediately increased, and values $>100 \mu \mathrm{mol} / \mathrm{l}$ were recognised as severe hyperhomocysteinaemia [4].

It has been demonstrated in both, in vitro and in vivo systems, that high concentration of HCy cause damage of endothelial cells, inhibited expression of endothelial nitric oxide synthase, induce oxidative stress, enhance leukocyte recruitment, activate matrix metalloproteinases (MMP)-9, and promote proliferation of smooth myocytes $[5,6]$. Thus, hyperhomocysteinaemia is currently recognised as an important risk factor of several cardiovascular disorders, including atherogenesis and thrombosis. Regarding the latter, it was estimated that the HCy serum concentration above $16.6 \mu \mathrm{mol} / \mathrm{l}$ may be responsible for a 2- to 5 -fold higher risk of venous thrombosis (VT) [7-9].

As mentioned previously, hyperhomocysteinaemia may be due to abnormal activity of enzymes engaged in HCy metabolism, mainly MTHFR. Apart from folate and 


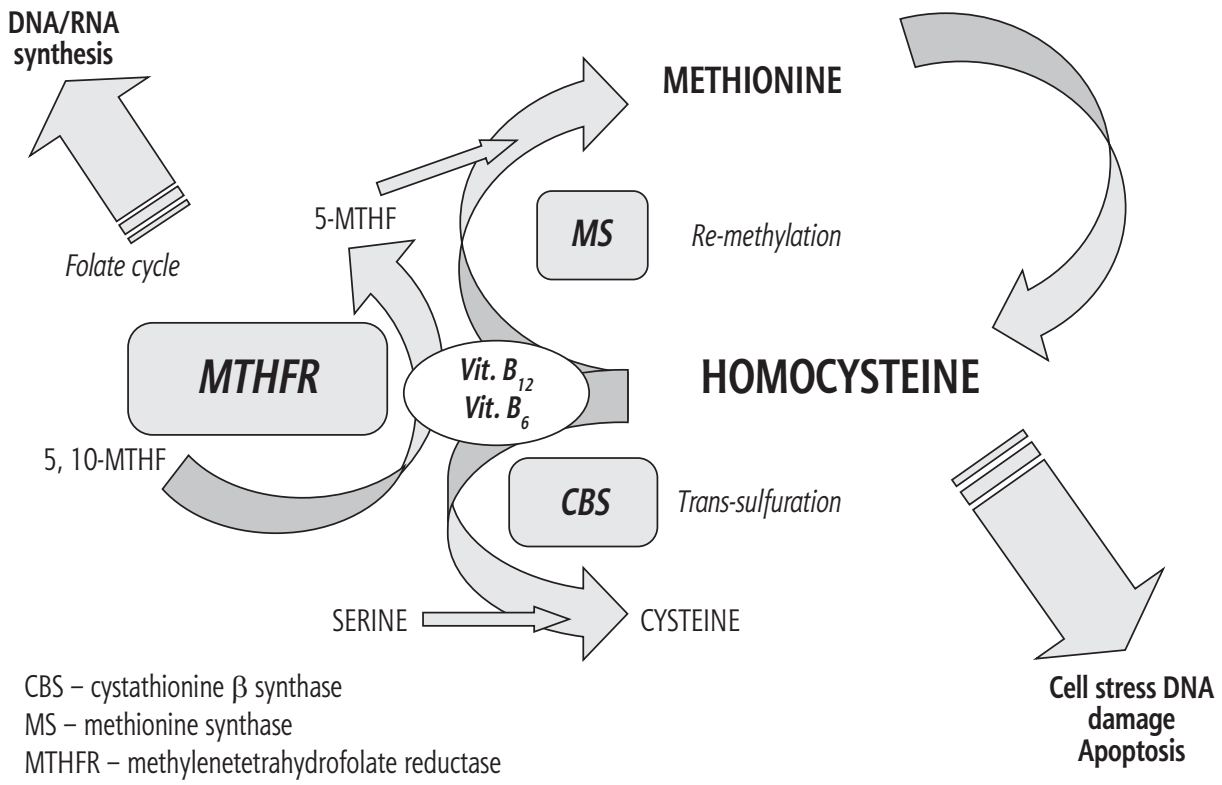

Fig. 1. Schematic representation of the main metabolic pathways involved in homocysteine metabolism (description in text)

vitamin B deficiencies, decreased activity of MTHFR may result from some molecular variations of gene encoding for this enzyme, characterised as single nucleotide polymorphisms (SNPs).

\section{MTHFR POLYMORPHISMS}

The human MTHFR gene is composed of 20 kilobase pairs, organised in 11 exons and located in chromosome 1 p36.3 [10,11]. Until now there have been over 40 identified SNPs associated with this gene; however, two of them seem to be the most clinically relevant functional variants: C667T in exon 4 and A1298C in exon 7 [12].

\section{C677T}

The most common MTHFR polymorphism (C677T) leads to substitution of an alanine by a valine residue. This change results in thermolability of the enzyme and affects its catalytic activity at $37^{\circ} \mathrm{C}[13]$, followed by suppression of remethylation pathway and increased risk of hyperhomocysteinaemia. Indeed, it has been proven that individuals bearing the CT genotype had approximately $65 \%$ of wild-type enzyme activity, with plasma concentrations of $\mathrm{HCy} 3-12 \%$ higher than those with the CC genotype. Furthermore, in TT homozygotes MTHFR activity reached $30 \%$ of the CC homozygotes, whereas HCy levels were 11-32\% higher as compared to wild-type homozygotes [14-17]. It is noteworthy that both, CT and TT genotypes do not necessarily lead to increased HCy levels, especially with a sufficient folate supply [18]. Conversely, deficiencies of the folate and vitamin $B_{6}$ and $B_{12}$ in these individuals may result in intermediate or severe hyperhomocysteinaemia $[19,20]$.
It has been demonstrated that MTHFR C677T SNP was associated with a significant risk of neural tube defects in the developing foetus, as well as repetitive miscarriages and cardiovascular disorders in adults [1, 21-23]. However, despite proven correlation between the above-mentioned risk of cardiovascular disorders and $677 \mathrm{~T}$ allele prevalence, the contribution of this MTHFR variant to the increased risk of vein thrombosis remains equivocal. The results of studies focused on that issue have shown large discrepancies, which may be due to a highly heterogeneous distribution of MTHFR SNP worldwide [24-26]. The frequency of 677T allele was reported as being low in Africans (6-10\%), relatively high in Caucasians (17-50\%), and highest in the Mexican population (over the 50\%) (Fig. 2) [27]. Interestingly, there is a north-to-south increase in the frequency of this allele in Europe and North America, whereas a reverse trend has been observed in China, India, and Pakistan [28]. Of note, several studies have shown a negative correlation between $677 \mathrm{~T}$ occurrence and longevity in various populations. Thus, since the presence of $677 \mathrm{~T}$ variant increases the risk of cardiovascular problems (including those with fatal outcome), due to a kind of negative selection its prevalence in older patients is relatively low, as compared to the general population [29-31].

\section{$\mathrm{A} 1298 \mathrm{C}$}

The next clinically relevant MTHFR polymorphism (A1298C) leads to substitution of a glutamate to alanine in the enzyme amino acid sequence. Also, this exchange, although to a lesser extent than for the previously described C677T SNP, was shown to affect enzyme activity and resulted in decreased concentrations of HCy in the 


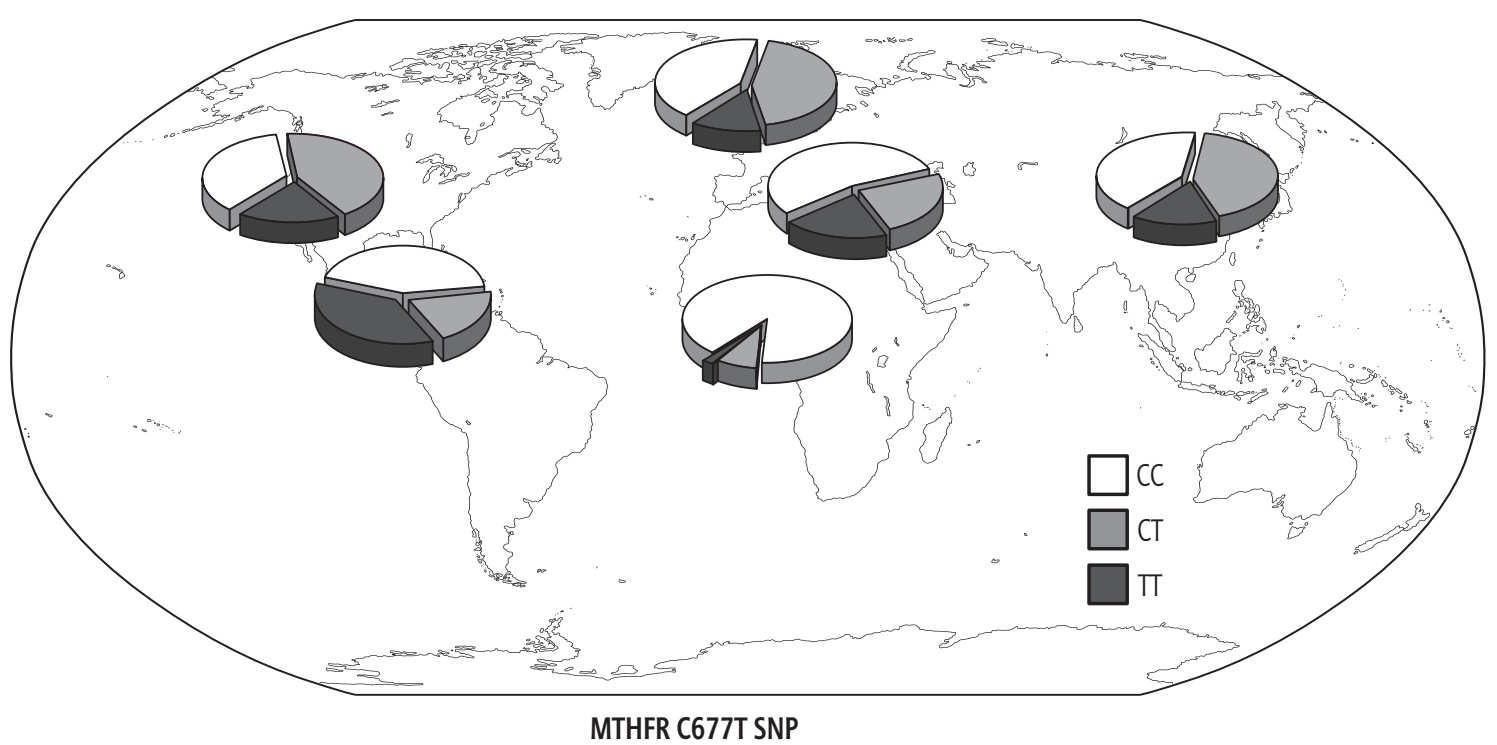

Fig. 2. Worldwide distribution of MTHFR C677T polymorphism (description in text)

serum of patients bearing the $1298 \mathrm{C}$ allele [32]. Therefore, this polymorphism was also supposed to be a risk factor for neural-tube defects [33] and congenital heart diseases [34]. Again, similarly to C677T SNP, the association of A1298C SNP with venous thrombosis is controversial.

In contrast to the above-mentioned C677T polymorphism, the distribution of A1298C SNP is poorly recognised, mainly due to its less pronounced effect on enzyme activity. However, the prevalence of $1298 \mathrm{C}$ variant in Central Europe seems to be higher than in West Africa, and also, contrary to 677T allele, in Mexico [27, 35]. According to a hypothesis concerning the origin of the observed frequency of MTHFR SNPs among the global population, such a distribution pattern may result from specific gene-nutrient interactions (including different nutritional habits, various exposure to UV radiation, etc.) $[27,36]$.

\section{METHYLENETETRAHYDROFOLATE REDUCTASE SINGLE NUCLEOTIDE POLYMORPHISMS IN VENOUS THROMBOSIS}

Although both of the MTHFR SNPs described above are considered as examples of genetically determined thrombophilia, as mentioned previously, their association with VT remains unclear. This discrepancy is especially obvious, when compared to "classical" representatives - defective variants of coagulation factors - factor V R506Q (better known as factor Leiden), and prothrombin A20210G SNPs, or relatively rare mutations of natural anticoagulants - protein $S$ or protein C. In contrast to them, the relationship between MTHFR SNPs and coagulopathy is indirect and more complex, especially since it is closely related to the dietary and/or metabolic condition of the patient. Furthermore, this analysis is further impeded by the uneven allele distribution among various ethnic groups, which may affect the significance of studies undertaken so far.

\section{Pro}

Several studies have suggested an association between MTHFR C677T SNP and increased risk of VT, mainly in Asian populations, including Far Eastern and Middle Eastern countries. Abudureheman et al. [37] investigated this connection in VT patients originating from two ethnic groups of Uygur and Han, from the Xinjiang Autonomous Region in China. The frequency of MTHFR 677TT genotype was $28.38 \%$ in Uygur VT patients and $27.03 \%$ in Han VT patients, versus $12.79 \%$ and $14.92 \%$ in respective control individuals. Similar results were reported by Yin et al. in a case-control study conducted in Shandong Province in China [38]. Also, Jang et al. postulated that the presence of MTHFR 677TT genotype was associated with an increased risk of VT in Koreans [39]. The authors also included the MTHFR A1298C in their analysis. However, they did not find any association between the latter SNP and VT occurrence in that population.

Very similar data were obtained by Kreidy et al. in Lebanese patients with VT [40]. Again only MTHFR $677 \mathrm{~T}$ allele, but not $1298 \mathrm{C}$, was associated with the increased risk of morbidity.

Tawfik et al. have shown that in the Egyptian population the $677 \mathrm{~T}$ allele may be considered as a significant risk factor of thrombosis since the TT genotype was present in $51 \%$ of VT patients, whereas its frequency in the control group was only $4.1 \%$ [41].

The association of MTHFR 677TT genotype with an increased risk of VT was also reported in patients from central Iran [42]. The frequency of TT homozygotes in a VT group was significantly higher $(11.1 \%)$ than in healthy controls (3.9\%). The same observation was published by Kupeli et al. in relation to the Turkish population [43]. Moreover, the MTHFR 677T allele was strongly 
associated with the occurrence of pulmonary embolism in patients from the western region of the Black Sea [44].

The increased risk of VT being associated with $677 \mathrm{~T}$ variant was also reported in Italy by Signorelli et al. [45]. In a small Russian study conducted by Shevela et al., the presence of this MTHFR variant increased the risk of VT up to 2-fold, as compared to wild allele [46].

Also, in South America, studies carried out among Chilean and Colombian populations have suggested that C677T polymorphism may be considered as a molecular risk marker for deep vein thrombosis, especially in Chilean patients [47].

A large meta-analysis concerning possible contribution of 28 major polymorphisms in 21 genes to VT development, performed by Gohil et al. in 126,525 cases and 184,068 controls from various ethnic groups, has confirmed the clinical relevance of MTHFR 677T allele only in Chinese and Thai populations [48]. However, in case of such significant geographical and ethic diversity in SNP distribution, the value of a large meta-analysis may be at least questionable.

\section{Contra}

In contrast to the reports mentioned above, some studies have negated the association of MTHFR SNPs with development of VT. No such relationship was reported by Ayala et al. with regard to the Colombian population [49], as well as to VT patients in Northern Europe. In a Norwegian study by Naess et al. the 677TT genotype was present in both, VT and control groups, with the same frequency of $9 \%$ and $8 \%$, respectively [50]. Similar observation was confirmed by Simone et al. [51], and in a large case-control Dutch study involving 4375 VT patients and 4856 control subjects [52]. Nevertheless, despite no clinically relevant interaction between MTHFR SNPs and other thrombophilia-associated polymorphisms (factor V Leiden and prothrombin G20210A variant) regarding thrombosis occurrence, it has been found that $677 \mathrm{~T}$ allele significantly increases the VT risk in women using oral contraceptives [51].

\section{CONCLUSIONS}

It is noteworthy that factor Leiden and prothrombin G20210A SNP were found in more than $50 \%$ of patients with inherited thrombophilia [53], and in approximately $30 \%$ and $6 \%$ of venous thrombosis-suffering individuals, respectively $[7,54]$. However, as mentioned previously, the occurrence of MTHFR SNPs, especially 677T allele, may affect more than $50 \%$ of the general population, e.g. in Central Europe. Such a high prevalence of these SNPs cannot be ignored, especially when combined with other pro-thrombotic risk factors - oral contraceptives, immobility, pregnancy, cancer, age, and gender [55-57]. Therefore, we postulate that at least MTHFR C677T SNP should be included in genetic screening. It seems reasonable especially in cases of recurrent thrombosis, positive family history, or VT episodes in young patients, but also for patients from populations with high prevalence of the mentioned SNP. Furthermore, such screening may be very useful in patients with high risk of hyperhomocysteinaemia due to dietary deficiencies - e.g. after gastric surgery, or abnormalities in intestinal absorption. In these cases the MTHFR SNPs-based rationale for intensive folate and $B$ vitamin supplementation would enable more effective anti-thrombotic protection. Thus, although recognised as rather weak single risk factors of venous thrombosis, polymorphisms of MTHFR cannot be underestimated and still require our attention.

The study was supported by the individual research grant of the Polish Society of Phlebology and LEK-AM pharmaceutical company.

\section{References}

1. Brustolin S., Giugliani R., Félix T.M. Genetics of homocysteine metabolism and associated disorders. Braz J Med Biol Res 2010; 43: $1-7$.

2. Trimmer E.E. Methylenetetrahydrofolate reductase: biochemical characterization and medical significance. Curr Pharm Des 2013; 19: 2574-2593.

3. Cheng X. Updating the relationship between hyperhomocysteinemia lowering therapy and cardiovascular events. Cardiovasc Ther 2013; 31: e19-e26.

4. Maron B.A., Loscalzo J. Should hyperhomocysteinemia be treated in patients with atherosclerotic disease? Curr Atheroscler Rep 2007; 9: 375-383.

5. da Cunha A.A., Scherer E., da Cunha M.J., Schmitz F., Machado F.R., Lima D.D., Delwing D., Wyse A.T. Acute hyperhomocysteinemia alters the coagulation system and oxidative status in the blood of rats. Mol Cell Biochem 2012; 360: 205-214.

6. Munjal C., Givvimani S., Qipshidze N., Tyagi N., Falcone J.C., Tyagi S.C. Mesenteric vascular remodeling in hyperhomocysteinemia. Mol Cell Biochem 2011; 348: 99-108.

7. Darvall K.A., Sam R.C., Adam D.J., Silverman S.H., Fegan C.D., Bradbury A.W. Higher prevalence of thrombophilia in patients with varicose veins and venous ulcers than controls. J Vasc Surg 2009; 49: 1235-1241.

8. den Heijer M., Blom H.J., Gerrits W.B., Rosendaal F.R., Haak H.L., Wijermans P.W., Bos G.M. Is hyperhomocysteinaemia a risk factor for recurrent venous thrombosis? Lancet 1995; 345 : 882-885.

9. Köktürk N., Kanbay A., Aydoğdu M., Özyılmaz E., Bukan N., Ekim N. Hyperhomocysteinemia prevalence among patients with venous thromboembolism. Clin Appl Thromb Hemost 2011; 17: 487-493.

10. Goyette P., Sumner J.S., Milos R., Duncan A.M., Rosenblatt D.S., Matthews R.G., Rozen R. Human methylenetetrahydrofolate reductase: isolation of cDNA, mapping and mutation identification. Nat Genet 1994; 7: 195-200.

11. Mendonca S., Gupta D., Gupta A. Segmental renal artery thrombosis secondary to methylene tetrahydrofolate reductase mutation: an unusual presentation. Iran J Kidney Dis 2012; 6: 464-466. 
12. Rai V., Yadav U., Kumar P. Prevalence of methylenetetrahydrofolate reductase C677T polymorphism in eastern Uttar Pradesh. Indian J Hum Genet 2012; 18: 43-46.

13. Matthews R.G. Methylenetetrahydrofolate reductase: a common human polymorphism and its biochemical implications. Chem Rec 2002; 2: 4-12.

14. Brattström L., Wilcken D.E., Ohrvik J., Brudin L. Common methylenetetrahydrofolate reductase gene mutation leads to hyperhomocysteinemia but not to vascular disease: the result of a meta-analysis. Circulation 1998; 98: 2520-2526.

15. Husemoen L.L., Thomsen T.F., Fenger M., Jørgensen H.L., Jørgensen T. Contribution of thermolabile methylenetetrahydrofolate reductase variant to total plasma homocysteine levels in healthy men and women. Inter 99 (2). Genet Epidemiol 2003; 24: 322-330.

16. Kumar J., Garg G., Kumar A., Sundaramoorthy E., Sanapala K.R., Ghosh S., Karthikeyan G., Ramakrishnan L., Indian Genome Variation Consortium, Sengupta S. Single nucleotide polymorphisms in homocysteine metabolism pathway genes: association of CHDH A119C and MTHFR C677T with hyperhomocysteinemia. Circ Cardiovasc Genet 2009; 2: 599-606.

17. Waśkiewicz A., Piotrowski W., Broda G., Sobczyk-Kopcioł A., Płoski R. Impact of MTHFR C677T gene polymorphism and vitamins intake on homocysteine concentration in the Polish adult population. Kardiol Pol 2011; 69: 1259-1264.

18. Cattaneo M., Tsai M.Y., Bucciarelli P., Taioli E., Zighetti M.L., Bignell M., Mannucci P.M. A common mutation in the methylenetetrahydrofolate reductase gene (C677T) increases the risk for deep-vein thrombosis in patients with mutant factor $\mathrm{V}$ (factor V:Q506). Arterioscler Thromb Vasc Biol 1997; 17: 1662-1666.

19. Eichinger $S$. Are B vitamins a risk factor for venous thromboembolism? Yes. J Thromb Haemost 2006; 4: 307-308.

20. Sam R.C., Burns P.J., Hobbs S.D., Marshall T., Wilmink A.B., Silverman S.H., Bradbury A.W. The prevalence of hyperhomocysteinemia, methylene tetrahydrofolate reductase C677T mutation, and vitamin B12 and folate deficiency in patients with chronic venous insufficiency. J Vasc Surg 2003; 38: 904-908.

21. Cao Y., Xu J., Zhang Z., Huang X., Zhang A., Wang J., Zheng Q., Fu L., Du J. Association study between methylenetetrahydrofolate reductase polymorphisms and unexplained recurrent pregnancy loss: a meta-analysis. Gene 2013; 514: 105-111.

22. Hoțoleanu C., Chouky E. Hyperhomocysteinemia and methylenetetrahydrofolate reductase polymorphism in a patient with coronary artery disease and repetitive miscarriages. Rom J Intern Med 2012; 50: 313-316.

23. Zhang T., Lou J., Zhong R., Wu J., Zou L., Sun Y., Lu X., Liu L., Miao X., Xiong G. Genetic variants in the folate pathway and the risk of neural tube defects: a meta-analysis of the published literature. PLoS One 2013; 8: e59570.

24. Dajani R., Fathallah R., Arafat A., Abdulqader M.E., Hakooz N., Al-Motassem Y., El-Khateeb M. Prevalence of MTHFR C677T single nucleotide polymorphism in genetically isolated populations in Jordan. Biochem Genet 2013; 51: 780-788.

25. Wilcken B., Bamforth F., Li Z., Zhu H., Ritvanen A., Renlund M., Stoll C., Alembik Y., Dott B., Czeizel A.E., Gelman-Kohan Z., Scarano G., Bianca S., Ettore G., Tenconi R., Bellato S., Scala I., Mutchinick O.M., López M.A., de Walle H., Hofstra R., Joutchenko L., Kavteladze L., Bermejo E., Martínez-Frías M.L., Gallagher M., Erickson J.D., Vollset S.E., Mastroiacovo P., Andria G., Botto L.D. Geographical and ethnic variation of the $677 \mathrm{C}>\mathrm{T}$ allele of 5,10 methylenetetrahydrofolate reductase (MTHFR): findings from over 7000 newborns from 16 areas worldwide. J Med Genet 2003; 40: 619-625.

26. Yapijakis C., Serefoglou Z., Nixon A.M., Vylliotis A., Ragos V., Vairaktaris E. Prevalence of thrombosis-related DNA polymorphisms in a healthy Greek population. In Vivo 2012; 26: 1095-1101.

27. Semmler A., Moskau S., Lutz H., Meyer P., Linnebank M. Haplotype analysis of the 5,10 - methylenetetrahydrofolate reductase (MTHFR) c.1298A $>$ C (E429A) polymorphism. BMC Res Notes 2011; 4: 439.

28. Yang B., Liu Y., Li Y., Fan S., Zhi X., Lu X., Wang D., Zheng Q., Wang Y., Wang Y., Sun G. Geographical distribution of MTHFR C677T, A1298C and MTRR A66G gene polymorphisms in China: findings from 15357 adults of Han nationality. PLoS One 2013; 8: e57917.

29. Hadhri S., Rejab M.B., Guedria H., Ifa L., Chatti N., Skouri H. Factor V Leiden, prothrombin 20210G $>$ A, MTHFR 677C $>$ T and $1298 \mathrm{~A}>\mathrm{C}$, and homocysteinemia in Tunisian blood donors. J Clin Lab Anal 2012; 26: 167-173.

30. Matsushita S., Muramatsu T., Arai H., Matsui T., Higuchi S. The frequency of the methylenetetrahydrofolate reductase-gene mutation varies with age in the normal population. Am J Hum Genet 1997; 61: 1459-1460.

31. Todesco L., Angst C., Litynski P., Loehrer F., Fowler B., Haefeli W.E. Methylenetetrahydrofolate reductase polymorphism, plasma homocysteine and age. Eur J Clin Invest 1999; 29: 10031009.

32. Cunha A.L., Hirata M.H., Kim C.A., Guerra-Shinohara E.M., Nonoyama K., Hirata R.D. Metabolic effects of C677T and A1298C mutations at the MTHFR gene in Brazilian children with neural tube defects. Clin Chim Acta 2002; 318: 139-143.

33. van der Put N.M., Gabreëls F., Stevens E.M., Smeitink J.A., Trijbels F.J., Eskes T.K., van den Heuvel L.P., Blom H.J. A second common mutation in the methylenetetrahydrofolate reductase gene: an additional risk factor for neural-tube defects? Am J Hum Genet 1998; 62: 1044-1051.

34. Zidan H.E., Rezk N.A., Mohammed D. MTHFR C677T and A1298C gene polymorphisms and their relation to homocysteine level in Egyptian children with congenital heart diseases. Gene 2013; 529: 119-124.

35. Guéant-Rodriguez R.M., Guéant J.L., Debard R., Thirion S., Hong L.X., Bronowicki J.P., Namour F., Chabi N.W., Sanni A., Anello G., Bosco P., Romano C., Amouzou E., Arrieta H.R., Sánchez B.E., Romano A., Herbeth B., Guilland J.C., Mutchinick O.M. Prevalence of methylenetetrahydrofolate reductase 677T and 1298C alleles and folate status: a comparative study in Mexican, West African, and European populations. Am J Clin Nutr 2006; 83: 701-707.

36. Yafei W., Lijun P., Jinfeng W., Xiaoying Z. Is the prevalence of MTHFR C677T polymorphism associated with ultraviolet radiation in Eurasia? Am J Clin Nutr 2006; 83: 701-707.

37. Abudureheman K., Mahemuti A., Xia Y.N., Hu X.M. Association between gene polymorphisms of methylenetetrahydrofolate reductase and plasma homocysteine in Uygur patients with venous thromboembolism. Zhonghua Xin Xue Guan Bing Za Zhi 2012; 40: 1030-1036.

38. Yin G., Yan L., Zhang Z., Chen K., Jin X. C677T methylenetetrahydrofolate reductase gene polymorphism as a risk factor involved in venous thromboembolism: a population-based case-control study. Mol Med Rep 2012; 6: 1271-1275.

39. Jang M.J., Jeon Y.J., Choi W.I., Choi Y.S., Kim S.Y., Chong S.Y., Oh D., Kim N.K. The $677 \mathrm{C}>\mathrm{T}$ mutation of the MTHFR gene 
increases the risk of venous thromboembolism in Koreans and a meta-analysis from Asian population. Clin Appl Thromb Hemost 2013; 19: 309-314.

40. Kreidy R., Waked M., Stephan E., Irani J., Chemali R., Jureidini I., Irani-Hakime N. Acquired and genetic risk factors for deep vein thrombosis of lower extremities among Lebanese patients. J Med Liban 2012; 60: 24-29.

41. Tawfik N.M., Deeb M.E., Nasr A.S. Role of soluble P-selectin and methylenetetrahydrofolate reductase gene polymorphisms $(677 \mathrm{C}>\mathrm{T})$ in Egyptian patients with venous thromboembolism. Blood Coagul Fibrinolysis 2012; 23: 537-542.

42. Pourgheysari B., Boroujeni H.R., Hasheminia A.M., Drees F PLA2 polymorphism of platelet glycoprotein IIb/IIIa but not Factor V Leiden and prothrombin G20210A polymorphisms is associated with venous thromboembolism and more recurrent events in central Iran. Blood Coagul Fibrinolysis 2013; 24: 471-476.

43. Kupeli E., Verdi H., Simsek A., Atac F.B., Eyuboglu F.O. Genetic mutations in Turkish population with pulmonary embolism and deep venous thrombosis. Clin Appl Thromb Hemost 2011; 17: e87-e94.

44. Tug E., Aydin H., Kaplan E., Dogruer D. Frequency of genetic mutations associated with thromboembolism in the Western Black Sea Region. Intern Med 2011; 50: 17-21.

45. Signorelli S.S., Fiore V., Puccia G., Mastrosimone G., Anzaldi M. Thrombophilia in patients with lower limbs deep veins thrombosis (LDVT). Results of a monocentric survey on 103 consecutive outpatients. Clin Appl Thromb Hemost 2013; 20: 589-593.

46. Shevela A.I., Egorov V.A., Sevost'ianova K.S., Novikova I.V., Filippenko M.L. Phlebothrombosis and congenital thrombophilia. Angiol Sosud Khir 2011; 17: 95-99.

47. Guzmán N., Salazar L.A. Frequency of prothrombotic risk factors in patients with deep venous thrombosis and controls: their implications for thrombophilia screening in Chilean subjects. Genet Test Mol Biomarkers 2010; 14: 599-602.

48. Gohil R., Peck G., Sharma P. The genetics of venous thromboembolism. A meta-analysis involving approximately 120,000 cases and 180,000 controls. Thromb Haemostas 2009; 102: 360-370.

49. Ayala C., García R., Cruz E., Prieto K., Bermúdez M. Homocysteine levels and polymorphisms of MTHFR and CBS genes in Colombian patients with superficial and deep venous thrombosis. Biomedica 2010; 30: 259-267.

50. Naess I.A., Christiansen S.C., Romundstad P.R., Cannegieter S.C., Blom H.J., Rosendaal F.R., Hammerstrøm J. Prospective study of homocysteine and MTHFR 677TT genotype and risk for venous thrombosis in a general population: results from the HUNT 2 study. Br J Haematol 2008; 141: 529-535.

51. Simone B., De Stefano V., Leoncini E., Zacho J., Martinelli I., Emmerich J., Rossi E., Folsom A.R., Almawi W.Y., Scarabin P.Y., den Heijer M., Cushman M., Penco S., Vaya A., Angchaisuksiri P., Okumus G., Gemmati D., Cima S., Akar N., Oguzulgen K.I., Ducros V., Lichy C., Fernandez-Miranda C., Szczeklik A., Nieto J.A., Torres J.D., Le Cam-Duchez V., Ivanov P., Cantu-Brito C., Shmeleva V.M., Stegnar M., Ogunyemi D., Eid S.S., Nicolotti N., De Feo E., Ricciardi W., Boccia S. Risk of venous thromboembolism associated with single and combined effects of factor $\mathrm{V}$ Leiden, prothrombin 20210A and methylenetetrahydrofolate reductase C677T: a meta-analysis involving over 11,000 cases and 21,000 controls. Eur J Epidemiol 2013; 28: 621-647.

52. Bezemer I.D., Doggen C.J., Vos H.L., Rosendaal F.R. No association between the common MTHFR 677C-T polymorphism and venous thrombosis: results from the MEGA study. Arch Intern Med 2007; 167: 497-501.
53. Rosendaal F.R. Venous thrombosis: the role of genes, environment, and behavior. Hematology Am Soc Hematol Educ Program 2005; 1-12.

54. Cumming A.M., Keeney S., Salden A., Bhavnani M., Shwe K.H., Hay C.R. The prothrombin gene G20210A variant: prevalence in a U.K. anticoagulant clinic population. Br J Haematol 1997; 98: 353-355.

55. Arslan S., Manduz S., Epöztürk K., Karahan O., Akkurt I. Association of deep venous thrombosis with prothrombotic gene polymorphism identified in lung cancer cases. Mol Biol Rep 2011; 38: 2395-2400.

56. Ferreira-Fernandes H., Costa P.N., Fernandes H.F., Araújo-Neto A.P., Motta F.J., Canalle R., Yoshioka F.K., Guerreiro J.F., Burbano R.R., Rey J.A., Pinto G.R. Prevalence of variants that confer risk for venous thromboembolism in an elderly population of northeastern Brazil. Genet Mol Res 2013; 12: 3698-3707.

57. Hussein A.S. High prevalence of three prothrombotic polymorphisms among Palestinians: factor V G1691A, factor II G20210A and methylenetetrahydrofolate reductase C677T. J Thromb Thrombolysis 2012; 34: 383-387. 